\title{
MÉTODOS ANALÍTICOS NO CONTROLE MICROBIOLÓGICO DA ÁGUA PARA CONSUMO HUMANO
}

\author{
Analithical methods for water microbiological control for human consumtion
}

\author{
Janine Maria Pereira Ramos Bettega ${ }^{1}$, Maria Rosa Machado ${ }^{2}$, Mayra Presibella ${ }^{3}$, \\ Grazielle Baniski $^{4}$, Carlos de Almeida Barbosa ${ }^{5}$
}

\begin{abstract}
RESUMO
A fim de realizar a quantificação de coliformes totais e fecais no decorrer das etapas de tratamento da água captada pela Companhia de Saneamento do Paraná (SANEPAR) Curitiba-PR, foram utilizadas três técnicas de análise microbiológica: (1) a técnica oficial preconizada pela Vigilância Sanitária, (2) Kit "A", (3) Kit "B". As metodologias foram validadas através de controles positivos e negativos. Os métodos utilizados apresentaram resultados extremamente homogêneos nas amostras pré-tratadas e também quando as amostras haviam passado pelos processos de purificação, porém, algumas discrepâncias entre os métodos avaliados foram detectadas em etapas intermediárias do tratamento da água. A utilização de Kits no controle microbiológico da água é muito prática porque elimina as etapas de preparação e esterilização dos meios de cultura em laboratório, porém deve-se analisar cuidadosamente o custo-benefício, bem como a sensibilidade e especificidade dos produtos disponíveis no mercado. O Kit "B" emprega um método enzimático, ao invés do método tradicional e Kit "A", que utilizam ambos: a turvação e formação de gás para a detecção o crescimento bacteriano. O kit " B" apresentou resultados similares aos outros dois métodos, mas com as vantagens de apresentar resultados extremamente claros e levar a metade do tempo para a obtenção dos resultados.
\end{abstract}

Termos para indexação: Água, coliformes totais, coliformes fecais; análise microbiológica da água, tratamento da água.

\begin{abstract}
In order to carry out the quantification of total and fecal coliforms in elapsing of the stages of water treatment by SANEPAR, Paraná State, three different techniques of microbiological analysis had been used: (1) the official technique praised by the Sanitary Monitoring; (2) Kit "A" and (3) Kit "B". The three methodologies of the water microbiological analysis had been validated through positive and negative controls. The used methods had presented extremely homogeneous results when the samples were contaminated and also when the samples had passed through the purification processes, however, some discrepancies among the evaluated methods had been detected in intermediate stages of the water treatment. The use of commercial Kits in water microbiological control is very practical because it eliminates the preparation and sterilization stages of the culture media in laboratory, however, it is necessary to analise carefully the cost-bennefit, sensibility and specifity of disposable products in market. The Kit "B" utilizes an enzymatic method, instead the tradicional technique and Kit "A" use both: the dim and gas formation to detect bacterial growth. The Kit "B" had showed similar results to the other two techniques, but with the advantages of presenting extreme clear results and take a half of time in the results obtention.
\end{abstract}

Index terms: Water, total coliforms, fecal coliforms fecais water microbiological analysis, water treatment.

(Recebido para publicação em 3 de janeiro de 2005 e aprovado em 5 de abril de 2006)

\section{INTRODUÇÃO}

A abundância de água no planeta causa uma falsa sensação de recurso inesgotável. Segundo especialistas em meio ambiente, $95,1 \%$ da água é salgada, sendo imprópria para consumo humano. Dos 4,9\% restantes, $4,7 \%$ estão na forma de geleiras ou regiões subterrâneas de difícil acesso, e somente os $0,147 \%$ estão aptos para o consumo em lagos, nascentes e em lençóis subterrâneos (GALLETI, 1981; RAINHO, 1999).

Atualmente, 29 países não possuem água doce para toda a população. Em 2005, segundo a ONU (MACEDO, 2001), serão 48 países e em 2050 cerca de 50 países sem água em quantidade suficiente para toda a população. Enquanto em Nova York (USA), o consumo atinge cerca de 2000 litros/habitante/dia, na África, a média do continente é de 15 litros/habitante/dia (BIO, 1999).

As principais fontes de contaminação dos recursos hídricos são: esgotos de cidades sem tratamento que são lançados em rios e lagos; aterros sanitários que afetam os lençóis freáticos, os defensivos agrícolas que escoam com a chuva sendo arrastados para os rios e lagos, os garimpos que lançam produtos químicos, como o mercúrio, em rios e córregos e as indústrias que utilizam os rios como carreadores de seus resíduos tóxicos (EMPRAPA, 1994; RSC, 1992).

\footnotetext{
${ }^{1}$ Farmacêutica-Bioquímica Universidade Tuiuti do Paraná/UTP - Rua Marcelino Champagnat, 505 - Bairro Mercês - $80.710-250$ - Curitiba, PR.

${ }^{2}$ Farmacêutica-Bioquímica Universidade Tuiuti do Paraná/UTP - Rua Marcelino Champagnat, 505 - Bairro Mercês - 80.710-250 - Curitiba, PR.

${ }^{3}$ Farmacêutica-Bioquímica Universidade Tuiuti do Paraná/UTP - Rua Marcelino Champagnat, 505 - Bairro Mercês - $80.710-250$ - Curitiba, PR.

${ }^{4}$ Aluna do curso de Farmácia Universidade Tuiuti do Paraná/UTP.

${ }^{5}$ Técnico do Laboratório de Microbiologia Universidade Tuiuti do Paraná/UTP.
} 
Além da necessidade de economia, a reciclagem e a reutilização aparecem como alternativas para o uso racional da água. A reciclagem pode ser definida como o reaproveitamento de uma água utilizada para determinada função, apesar da alteração de suas qualidades físicoquímicas e microbiológicas em função do uso. $\mathrm{O}$ reaproveitamento pode ser feito em alguns casos antes que a água atinja a rede de esgotos (BRANDIMARTE, 1999).

Para que a água seja considerada potável, após o tratamento convencional os parâmetros físico-químicos e microbiológicos deverão estar de acordo com a Portaria ${ }^{\circ}$ 36, do Ministério da Saúde, de 19 de janeiro de 1990, que em seu Anexo apresenta as normas e o padrão de potabilidade da água destinada ao consumo humano, a serem observadas em todo o território nacional (BRASIL, 1990).

A avaliação da presença de organismos patogênicos na água é determinada pela presença ou ausência de um organismo indicador e sua respectiva população. $\mathrm{O}$ isolamento e identificação de cada tipo de microrganismo exige uma metodologia diferente e a ausência ou presença de um patógeno não exclui a presença de outros.

Para um microorganismo ser considerado indicador ideal, são necessárias algumas características, tais como: ser aplicável a todos os tipos de água, ter uma população mais numerosa no ambiente que outros patógenos, sobreviver melhor que os possíveis patógenos, possuir resistência equivalente a dos patogênicos aos processos de autodepuração e ser detectado por uma metodologia simples e barata. Infelizmente, não existe um indicador ideal de qualidade sanitária da água, mas sim alguns organismos que se aproximam das exigências referidas (CETESB, 1991; LEITÃO et al., 1988).

A Companhia de Saneamento do Paraná (SANEPAR) Curitiba-PR é o órgão responsável pelos serviços de abastecimento de água na região do Estado do Paraná, a fim de que este produto seja levado até as torneiras dos consumidores dentro dos padrões de potabilidade estabelecidos internacionalmente. Antes de chegar ao reservatório domiciliar, a água captada de superfícies passa por uma série de etapas de tratamento, visando adaptá-la para uso doméstico. Essas etapas incluem, na ordem: coagulação (adição de sulfato de alumínio que reage com a alcalinidade natural da água, formando hidróxido de alumínio); floculação (processo que transforma as impurezas em partículas mais densas que a água, os flocos); decantação (separação de partículas sólidas suspensas na água que tendem a se depositar); filtração (retenção dos flocos em suspensão e demais materiais que não decantaram através da passagem por substâncias porosas como areia e carvão); desinfecção (remoção de microrganismos presentes na água através da adição de cloro ou hipoclorito de cálcio) e fluoretação (a fim de prevenir cárie dentária infantil, adiciona-se flúor na água) (SANEPAR, 2004).

Visando resguardar a qualidade da água para o consumo humano foram avaliados, no presente estudo, alguns métodos de purificação da água captada pela SANEPAR no Estado do Paraná, através de parâmetros microbiológicos. Três metodologias distintas de detecção de coliformes totais e fecais na água, foram avaliadas e comparadas entre si.

\section{MATERIAL E MÉTODOS}

\section{Amostras analisadas}

Quantidades suficientes de água foram coletadas em frascos estéreis, em diversas etapas de tratamento pela Companhia de Saneamento do Paraná (SANEPAR), na cidade de Curitiba-PR, em julho de 2004, obtendo-se as seguintes amostras:

- Água "in natura" ou não tratada (IN)

- Água coagulada (C),

- Água decantada (D)

- Água tratada, pronta para consumo/distribuição (T)

\section{Metodologias utilizadas}

A fim de realizar a quantificação de coliformes totais e fecais nas amostras coletadas, foram utilizadas três metodologias diferentes. A primeira técnica utilizada (1) foi o método tradicional de tubos múltiplos, em conformidade com o Apha (1999). Esta metodologia foi empregada como padrão, por ser amplamente preconizada pela Vigilância Sanitária e outros órgãos regulamentadores, com a finalidade de comparar os resultados obtidos por dois "kits" produzidos por empresas diferentes disponíveis no mercado.

O método dos tubos múltiplos é realizado em duas etapas: na primeira, a amostra é inoculada em caldo lauril sulfato de sódio, o qual inibe a microbiota acompanhante e, ao mesmo tempo é um meio de enriquecimento para bactérias do grupo dos coliformes. Bactérias deste grupo causam turvação no meio com formação de gás, detectado em tubos de Duhran, após 48 horas de incubação a $35 \pm$ $2^{\circ} \mathrm{C}$. A segunda etapa é realizada através da inoculação de alçadas dos caldos lauril positivos em caldos seletivos para Escherichia coli (EC). Após incubação a $44,5^{\circ} \mathrm{C}$, durante 24 horas, ocorre turvação do caldo $\mathrm{EC}$ com formação de gás, quando positivos para coliformes fecais (ROMPRÉ et al., 2002). 
Outra técnica utilizada neste estudo para a detecção de coliformes (2), foi kit "A", que utiliza o mesmo princípio do método tradicional, utilizando os caldos lauril sulfato de sódio e EC.

Por fim, utilizou-se uma terceira técnica (3), o kit "B", que utiliza um outro princípio: a pesquisa de coliformes é detectada através da presença de uma enzima específica deste grupo bacteriano, a galactosidase, que hidrolisa um substrato cromógeno (X-gal) produzindo uma cor verdeazulada no meio. A presença de coliformes fecais é visualizada através da fluorescência, sob luz ultravioleta (UV), produzida pela hidrólise enzimática do substrato metilumbeliferil-galactosídeo (MUG); sendo que apenas os coliformes fecais produzem a enzima responsável pela hidrólise deste substrato. Se a amostra fluorescer sob luz UV, o tubo deve ser testado para a prova do indol. Esta prova consiste em adicionar cinco gotas do reativo de Kovacs; o aparecimento de cor vermelho-rósea na superfície do caldo dentro de 3 minutos confirma a presença de coliformes fecais, que são bactérias produtoras de indol.

No kit "B", as duas reações específicas para coliformes e coliformes fecais, são visualizadas simultaneamente, enquanto que nas metodologias empregadas pelo método tradicional e kit "A", cada reação ocorre separadamente, levando o dobro do tempo para a verificação do resultado.

A quantificação de coliformes e coliformes fecais nas três técnicas empregadas foi realizada através de um método simplificado de aproximação, denominado "Número Mais Provável" (NMP), também conhecido como "tubos múltiplos", sendo o resultado expresso em NMP por 100 mL (STANDARD METHODS, 1999). A leitura da técnica do NMP consiste em anotar os tubos turvos e com formação de gás, nos casos dos caldos lauril sulfato de sódio e caldo EC, e anotar a quantidade de tubos verdeazulados fluorescentes, no caso do caldo MUG. De posse destas anotações, os valores são comparados com a tabela do NMP (APHA, 1999) correspondente à técnica utilizada.

\section{Validação dos métodos}

Com o objetivo de validar as metodologias empregadas, foram realizados controles positivos $(\mathrm{CP})$ e negativos $(\mathrm{CN})$ para cada uma. Nos controles positivos $(\mathrm{CP})$, foi inoculada a cepa padrão de Escherichia coli (ATCC 25922) nos meios de cultura e incubados nas mesmas condições das amostras. Os controles negativos $(\mathrm{CN})$ consistem na incubação dos caldos nas mesmas temperaturas das amostras, porém sem a inoculação das mesmas.

\section{RESULTADOS E DISCUSSÃO}

$\mathrm{O}$ primeiro passo para o sucesso de qualquer metodologia é o processo de adequação às condições do laboratório, ou seja, é preciso validar a técnica antes de ser rotineiramente utilizada. As técnicas foram adequadamente validadas através da realização de controles positivos (CP) e controles negativos ( $\mathrm{CN}$ ), sendo que os resultados obtidos foram os esperados, ou seja, positivos para os $\mathrm{CP}$ (equivalentes a $\geq 6,9 \mathrm{NMP} / 100 \mathrm{~mL}$ ), e negativos para os $\mathrm{CN}$ (equivalentes a $<1,1 \mathrm{NMP} / 100 \mathrm{~mL}$ ) (Tabela 1, linhas 3 e 4).

Após a validação das metodologias, as amostras de água foram testadas. Utilizando o método tradicional, os resultados foram positivos para $\mathrm{CT}$ e $\mathrm{CF}$ (equivalentes $\mathrm{a} \geq 6,9$ NMP $100 \mathrm{~mL}$ ) para água não tratada (IN), captada pela SANEPAR. A mesma água foi submetida ao processo de coagulação (C), apresentando a mesma quantidade de coliformes totais (CT) que a água IN, porém houve diminuição do número de coliformes fecais (2,2 NMP/100 mL). Durante o processo de decantação da água (D), o número de coliformes totais foi reduzido $(3,6 \mathrm{NMP} / 100 \mathrm{~mL})$, enquanto que o número de CF foi zerado (Tabela 1). A água passou, então, pelo último processo de tratamento, que é a cloração e fluoretação. A quantidade de coliformes totais e fecais foi igualada ao mesmo número obtido no controle negativo, isto é, ausência de CT e $\mathrm{CF}$ (equivalentes a $<1,1 \mathrm{NMP} / 100 \mathrm{~mL}$ ).

As mesmas amostras de água foram testadas microbiologicamente utilizando o kit "A". As amostras de água não tratada (IN) e de água que passou por todos os processos de tratamento $(\mathrm{T})$, apresentaram os resultados esperados e idênticos aos obtidos pelo método oficial, ou seja, ausência de CT e CF e foram totalmente positivas para $\mathrm{CT}$ e $\mathrm{CF}$, respectivamente.

As amostras de água coagulada e decantada apresentaram resultados distintos dos obtidos pelo método oficial. Para água coagulada (C) e água decantada (D), foram encontrados 1,1 NMP/100 mL de CT e CF, uma quantidade menor que a obtida pelo método oficial (Tabela 1).

Os testes das mesmas amostras de água, realizados com o kit "B", mostraram resultados idênticos ao método oficial e kit "A" para as amostras in natura ( $\geq 6,9$ NMP/100 $\mathrm{mL}$ ) e amostras de água tratada (<1,1 NMP/100 mL). Esses resultados indicam que não há discrepâncias entre as metodologias quando as amostras estão realmente contaminadas, ou seja, na água não tratada, e quando as amostras já passaram pelos processos de tratamento (água tratada). As disparidades dos resultados em diferentes metodologias foram detectadas justamente nas amostras que estavam sendo tratadas, isto é, nas etapas intermediárias do processo. Nas amostras de água coagulada (C), foram encontrados 1,1 NMP/100 mL de CT e <1,1 NMP/100 mL de $\mathrm{CF}$, já na água decantada (D) foram encontrados $\geq 6,9 \mathrm{NMP} /$ $100 \mathrm{~mL}$ de CTe <1,1 NMP/100 mL de CF, utilizando o kit "B" (Tabela 1). 
TABELA 1 - Resultados obtidos na análise microbiológica da água para consumo humano, utilizando o Método oficial, Kit "A" e Kit "B":

\begin{tabular}{|c|c|c|c|}
\hline \multirow[b]{2}{*}{ Amostras/Controles } & \multicolumn{3}{|c|}{$\begin{array}{l}\text { Número de coliformes totais }(\mathrm{CT}) \text { e/ou fecais }(\mathrm{CF}) \text { encontrados nas amostras de } \\
\text { água captada pela SANEPAR e nos controles positivo (CP) e negativo (CN), } \\
\text { expressos em NMP/100 mL (limite de confiança 95\%) }\end{array}$} \\
\hline & Metodologia oficial & 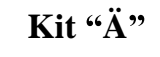 & Kit "B" \\
\hline \multirow[t]{2}{*}{$\mathbf{C N}$} & $\mathrm{CT}=<1,1$ & $\mathrm{CT}=<1,1$ & $\mathrm{CT}=<1,1$ \\
\hline & $\mathrm{CF}=<1,1$ & $\mathrm{CF}=<1,1$ & $\mathrm{CF}=<1,1$ \\
\hline \multirow[t]{2}{*}{$\mathbf{C P}$} & $\mathrm{CT}=>6,9$ & $\mathrm{CT}=>6,9$ & $\mathrm{CT}=>6,9$ \\
\hline & $\mathrm{CF}=>6,9$ & $\mathrm{CF}=>6,9$ & $\mathrm{CF}=>6,9$ \\
\hline \multirow[t]{2}{*}{ IN } & $\mathrm{CT}=>6,9$ & $\mathrm{CT}=>6,9$ & $\mathrm{CT}=>6,9$ \\
\hline & $\mathrm{CF}=>6,9$ & $\mathrm{CF}=>6,9$ & $\mathrm{CF}=>6,9$ \\
\hline \multirow[t]{2}{*}{$\mathbf{C}$} & $\mathrm{CT}=>6,9$ & $\mathrm{CT}=1,1$ & $\mathrm{CT}=1,1$ \\
\hline & $\mathrm{CF}=2,2$ & $\mathrm{CF}=1,1$ & $\mathrm{CF}=<1,1$ \\
\hline \multirow[t]{2}{*}{ D } & $\mathrm{CT}=3,6$ & $\mathrm{CT}=1,1$ & $\mathrm{CT}=1,1$ \\
\hline & $\mathrm{CF}=<1,1$ & $\mathrm{CF}=1,1$ & $\mathrm{CF}=<1,1$ \\
\hline \multirow[t]{2}{*}{$\mathbf{T}$} & $\mathrm{CT}=<1,1$ & $\mathrm{CT}=<1,1$ & $\mathrm{CT}=\langle 1,1$ \\
\hline & $\mathrm{CF}=<1,1$ & $\mathrm{CF}=<1,1$ & $\mathrm{CF}=<1,1$ \\
\hline
\end{tabular}

NMP - Número mais provável; $\mathrm{CN}$ - Controle negativo; $\mathrm{CP}$ - Controle positivo; IN - Água in natura (não tratada); C - Água coagulada; D - Água decantada; T - Água tratada; CT -Coliformes totais; CF - Coliformes fecais.

Para as amostras obtidas da água coagulada, o método mais sensível para detecção de coliformes totais e fecais foi a técnica tradicional, apresentando $\geq 6,9 \mathrm{NMP} /$ $100 \mathrm{~mL}$ e 2,2 NMP/100 mL respectivamente. Para a água decantada, a maior sensibilidade foi obtida pelo kit "B", que detectou $\geq 6,9 \mathrm{NMP} / 100 \mathrm{~mL}$ para $\mathrm{CF}$.

Porém, os resultados obtidos com amostras de água coagulada e decantada não podem ser utilizados como medidores da sensibilidade entre os métodos, pois são amostras instáveis, em que há a formação de partículas maiores (flocos), onde os microrganismos são aprisionados, dificultando a quantificação correta através das técnicas microbiológicas utilizadas.

O importante é que foi confirmado, através de metodologias de análise microbiológica de procedências distintas, que a água captada (que ainda não passou pelos processos de purificação), apresentou-se contaminada; e que a água tratada adequadamente já não apresentou contaminações pelos microrganismos testados.

\section{CONCLUSÕES}

- As três metodologias de análise microbiológica da água utilizadas neste estudo foram adequadamente validadas através de controles positivos e controles negativos.
- O tratamento da água realizado pela Companhia de Saneamento do Paraná (SANEPAR), na cidade de Curitiba-PR, em julho de 2004, eliminou a presença de microrganismos indicadores de contaminação de origem fecal, após a realização de todas as etapas do processo.

- As metodologias empregadas no presente estudo para a avaliação microbiológica da água apresentaram resultados homogêneos quando as amostras estavam sabidamente contaminadas (água não tratada) e também quando as amostras haviam passado pelos processos de purificação.

- As três diferentes metodologias de análise microbiológica das águas utilizadas apresentaram resultados heterogêneos quando se tratam de amostras analisadas durante o processo de purificação, principalmente as etapas de coagulação e decantação.

- As três metodologias empregadas podem ser utilizadas com sucesso para a análise de coliformes totais e fecais na água para consumo humano, em especial após o tratamento da água pelo sistema tradicional.

- O método tradicional é mais trabalhoso para ser executado, pois requer a preparação e esterilização dos caldos de cultura. Necessita, portanto, de um laboratório equipado com autoclave, vidrarias e outros equipamentos, além de técnicos bem treinados. 
- A técnica utilizada pelo kit "A" conserva as características do método tradicional, utilizando os mesmos meios de cultura, com a vantagem de já fornecer os meios estéreis.

- A metodologia empregada pelo kit "B" é baseada na presença e/ou ausência de enzimas específicas do metabolismo de bactérias dos grupos coliforme e coliforme fecal, apresentando maior clareza na visualização dos resultados e levando metade do tempo para a obtenção dos mesmos.

- A partir das análises das metodologias estudadas, os autores acreditam que o kit " B" é o mais indicado para a realização dos testes microbiológicos da água para consumo humano devido a sua praticidade, menor tempo de análise e clareza na visualização dos resultados, apesar de apresentar um custo mais elevado. Este custo, porém, é compensado, uma vez que os meios já vêm estéreis, o que elimina o uso de autoclave.

\section{REFERÊNCIAS BIBLIOGRÁFICAS}

BIO. Água no mundo. Revista Brasileira de Saneamento e Meio Ambiente, [S.1.], v. 10, n. 11, p. 41, jul./set. 1999.

BRANDIMARTE, A. L. Crise da água. Ciência Hoje, São Paulo, v. 26, n. 154, p. 36-42, out. 1999.

BRASIL. Portaria 36, de 19 de janeiro de 1990. Dispõe sobre a água para o consumo humano. Brasília, DF: Governo Federal, 1990.

CETESB. Procedimentos para utilização de testes de toxicidade no controle de efluentes líquidos. São Paulo, 1991. (Série Manuais).
EMPRESA BRASILEIRA DE PESQUISA AGROPECUÁRIA. Atlas do meio ambiente do Brasil. Brasília, DF: Terra Viva, 1994. 138 p.

GALLETI, P. A. Mecanizaýo agrícola: preparo do solo. Campinas: Instituto Campineiro de Ensino Agrícola, 1981. 220 p.

LEITÃO, M. F. F.; HAGLER, L. C. S. M.; HAGLER, A. N.; MENEZES, T. J. B. Tratado de microbiologia. São Paulo: Manole, 1988. $186 \mathrm{p}$.

MACEDO, J. A. B. Águas \& águas. São Paulo: Varela, 2001. $1000 \mathrm{p}$.

RAINHO, J. M. Planeta água. Revista Educação, São Paulo, v. 26, n. 221, p. 48-64, set. 1999.

ROMPRÉ, A.; SERVAIS, P.; BAUDART, J.; DE-ROUBIN, M. R.; LAURENT, P. Detection and enumeration of coliforms in drinking water: current methods and emerging. Journal of Microbiological Methods, [S.1.], v. 49, p. 31-54, 2002.

THE ROYAL SOCIETY OF CHEMISTRY, UNDERSTANDING OUR ENVIRONMENT. An introduction to environmental chemistry and pollution. London: Paston, 1992. 326 p.

SANEPAR. Saneamento. Disponível em: 〈ww'w.sanepar.com.br Acesso em: 20 out. 2004.

AMERICAN PUBLIC HEALTHASSOCIATION. Standard methods for the examination of water and wastewater. 20 . ed. Washington: American Public Health Association; AWWA; WPCF, 1999. 1569 p. 